\title{
Article
}

\section{Spatial Design Stimuli to Promote Wellness through Buildings' Design}

\author{
Ramadan, Amal and Kamel Ahmed, Ehab \\ Available at http://clok.uclan.ac.uk/33056/ \\ Ramadan, Amal and Kamel Ahmed, Ehab ORCID: 0000-0002-6737-9356 \\ (2019) Spatial Design Stimuli to Promote Wellness through Buildings' Design. \\ International Journal of Architecture, Engineering and Construction, 8 (4). pp. \\ 1-12. ISSN 1911-110X
}

It is advisable to refer to the publisher's version if you intend to cite from the work. http://dx.doi.org/10.7492/IJAEC.2019.023

For more information about UCLan's research in this area go to http://www.uclan.ac.uk/researchgroups/ and search for <name of research Group>.

For information about Research generally at UCLan please go to http://www.uclan.ac.uk/research/

All outputs in CLoK are protected by Intellectual Property Rights law, including Copyright law. Copyright, IPR and Moral Rights for the works on this site are retained by the individual authors and/or other copyright owners. Terms and conditions for use of this material are defined in the policies page.

\section{CLoK}

Central Lancashire online Knowledge www.clok.uclan.ac.uk

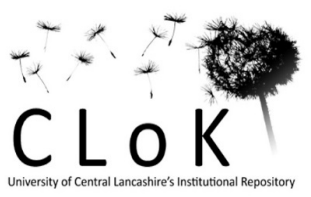


Spatial Psychologically-Supportive Design Stimuli [SPSDS]: To Promote Wellness through Buildings'

Design

\section{Introduction}

With the increased rate of Mental Health challenges, architecture is believed to play a significant role in supporting users' wellbeing. As such, this paper represents the results of the analyses of an extensive multidisciplinary literature review [720 sources] that tackles the relationship between users' wellbeing and the surrounding spatial environment. The investigation aims to define a set of all possible architectural design parameters that may affect users' psychological wellbeing within the space.

The paper commences by demonstrating the different stages of systematic analysis. NVivo was employed, as a secondary tool, to scrutinise the massive multi-disciplinary literature and to define all possible design stimuli affecting users' psychology and wellbeing.

The analysis identified fifteen psychologically supportive design stimuli [PSDS]; each of them was subject of further procedures of in-depth analysis queries that aim to define its main characteristics, impacts on users' psychology and wellbeing, and in which sense/intensity each stimulus could act either positively or negatively in the built environment.

\section{Methodology}

The analysis of the multidisciplinary literature occurred through five main phases:

\subsection{Defining the scope}

The first phase formed a primary search investigating literature on healing and supportive environments. This search formed an initial literature map of relevant published work and the different academic disciplines that investigated the topic. The used search terms were: healing environment, psychologically-supportive-design, restorative environment, and usercentred design. Additionally, combinations of keywords were employed, such as healing environments AND staff outcomes; healing environments AND healthcare design; design AND stress; healing environments AND stress; "evidence-based design" AND stress; "evidence-based design" AND outcomes; and "evidence-based design" AND the physical environment. 
A manual content analysis was performed to indicate the most frequently occurring design stimuli, through relevant studies that tackle users' wellbeing, attention restoration in a stressful environment, along with many substantial studies that tackle one's psychological wellbeing concerning a specific physical stimulus such as; solar light, flora, colours, view from windows, noise, privacy, etc.

\subsection{Investigating biophilic design}

Nature, view of nature, indoor plants and landscape design, were a common player in all the investigated reviews due to the important role they play in creating a supportive healing environment. Therefore, an independent phase of the review analysis investigated how the natural environment affects human psychology. Hence, an in-depth analysis of the biophilic design literature was conducted in this sense (see Ramadan et al. 2014).

\subsection{Multidisciplinary literature review}

The first phases of the analysis revealed that the topic was mainly deliberated through the published review of Psychology, Medicine and Architecture disciplines and their subdisciplines. The topic was subject of investigation through many psychological theories, such as space cognition, attention restoration theory, etc. Selected studies in medicine discussed the relationship between environment and health, somatic diseases and the role of therapeutic environment on human's health and wellbeing. However, the number of published studies through each discipline independently were not enough to formulate a 
thorough reliable review analysis. As such, a crucial need aroused to employ a

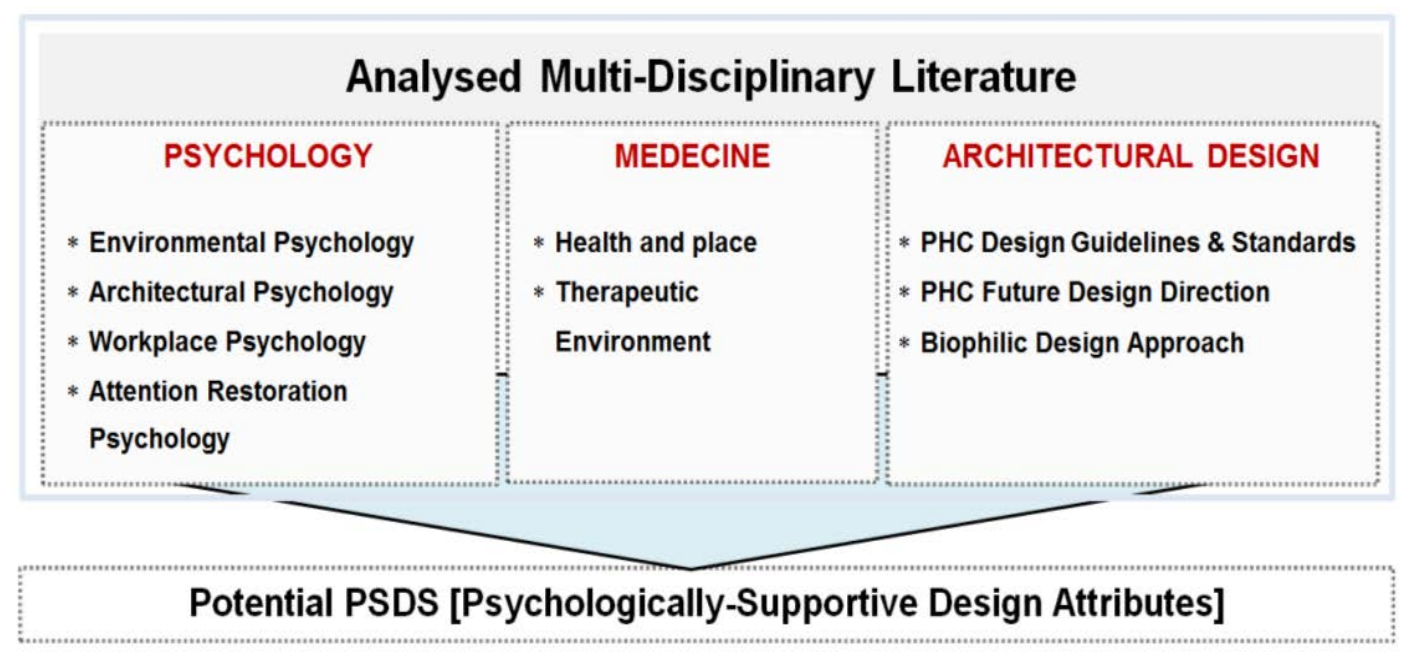

Figure 1. The investigated disciplines and sub-disciplines covered by the review analysis

multidisciplinary analysis to scrutinise the subject from its different theoretical perspectives.

The electronic search examined common databases: Science (Psychology), Social Sciences (Occupational Psychology), Medicine and Health Sciences (Evidence-based resources), Engineering (Architecture and Urban Planning). The examined databases included: PsychINFO, Medline, NICE Evidence Services, SCOPUS (Elsevier), Health Environment \& Work (HE\&W), Web of Science, British Psychological Society, American Psychological Association, Dissertation abstracts, Papers1st (conferences and paper abstracts, Web of Science, and WorldCat. As well, the search was run through the web library catalogues of the University of Nottingham, Ningbo China [UNNC], the University of Nottingham UK [UoN], Google Scholar search engine, and peer-reviewed internet sites on Google internet search engine. The search included documents dated from 1990 to November 2018, written in the English Language.

The search used the following keywords: evidence-based design, healing environment, healthcare design, restorative environment, space cognition, staff outcomes, stress, depression, staff satisfaction, environmental psychology, workplace psychology, nature and daylight, biophilic design. Additionally, a further search was based on the most frequently occurring authors' names, such as Roger Ulrich, Craig Zimrich, Alan Dinali, Ann Sloan Devlin and Allison B. Arneill. 
The investigated collections of literature were catalogued on EndNote, to be transferred to NVivo, for the following stage.

\subsection{NVivo Analysis}

The fourth phase of this study was a content analysis via NVivo. The analysis identified the frequently used Spatial Attributes expressions, through detecting key terms in various literature resources, coding important themes and concepts within the reviewed [720] sources, and finally coding this analysed information into themes (NVivo nodes). This phase identified multiple design parameters that could potentially affect users' psychology within any spatial environment.

An advanced word frequency query was conducted to establish only attributes related to the physical environment, by excluding supplementary basic words, such as users, using, environment, psychology ...etc. Yet, some of the resulted design-parameters had double meanings; for instance, the term 'level' could indicate a 'physical level' or 'level of satisfaction', 'level of blood pressure', etc. Many words were identified as of similar confusion, such as: lift, form, area, order, urban, visual, way, function, etc. Hence, a further extended text search queries, NVivo analysis, was conducted to exclude terms of irrelevant meanings.

This analysis phase successfully identified set of 35 design factors, the most discussed throughout the analysed literature, as follow: nature, area, light, measuring, spacing, view, placing, colour, color, plan, scaling, risk, infections, accession, forms, arts, noise, materials, air, visuals, patterns, privatisation, locations, home, green, ventilators, waters, landscaping, whiting, beds, walls, safety, spatially, sounds, and brightness.

The repetitive attributes listed above; e.g.: colours-colors, and green-nature, or those having close interrelated meanings, were grouped through the fifth phase of analysis to create further developed list of attributes, as explained in the following section.

\subsection{Defining Psychologically-Supportive Design Stimuli [PSDS]}

The fifth phase of analysis matched similar words and meanings under unified titles, through a sequence of text search queries for each design parameter independently. Text queries revealed that attributes such as areas, spacing, placing, plan, and location can be grouped 
under one title: 'Spatial Layout', while the attributes: measuring and scaling can be classified as 'Ergonomics'.

This phase of analysis resulted by the final fifteen design stimuli that could have a psychological impact on the built-environment users. These parameters were classified into two sets: functional and sensorial.

\begin{tabular}{|c|c|}
\hline 4. Layout/Operation [Functional Stimuli] & 5. Physical Environment [Sensorial Stimuli] \\
\hline $\begin{array}{l}\text { 1. Spatial Layout: } \\
\text { [2.areas, 5.Spacing, 7.Placing, 10.Plan, } \\
\text { 14.Asseccion, 23.Location, 33.Spatially] } \\
\text { 2. Ergonomics: } \\
\text { [4.Measuring and 11.Sacling] } \\
\text { 3. Staff Privacy: } \\
\text { [22.Privatization] } \\
\text { 4. Furniture: [24.Home, 30.beds] } \\
\text { 5. Safety \& Infection Control: } \\
\text { [12. Risk, 13.Infections, 32.Safety] }\end{array}$ & $\begin{array}{l}\text { 6. Nature: [1.Nature, } 25 . \text { Green, 28.Landscaping] } \\
\text { 7. Views: [6.View, 20.Visual] } \\
\text { 8. Light [3.Light, } 35 . \text { Brightness] } \\
\text { 9. Colours: [8.Colour, 9.Color, 29.Whiting] } \\
\text { 10. Art: [16.Arts] } \\
\text { 11. Finishing Materials \& Textures: } \\
\text { [18.materials, 31.Walls] } \\
\text { 12. Noise \& Sounds: [17.Noise] } \\
\text { 13. Shape \& Patterns: [15.Forms, 21.Pattems] } \\
\text { 14. Fresh Air \& Odours: [19.Air, 26.Ventilators] } \\
\text { 15. Water: [27.Waters] }\end{array}$ \\
\hline
\end{tabular}

Figure 2. Classification of the resulted 15 PSDS

As shown in Figure 2, five stimuli are classified as functional, while ten are sensorial. Yet, it is important to consider that functional stimuli also act as sensorial; e.g. efficient functional ergonomics studies could be reconsidered based on how people 'mentally' recognise and interpret ergonomics despite their apparent functional efficiency.

The word cloud (Figure 3), shows that 'area', 'spacing', 'placing', and 'plan' are significantly dominant in the analysed review. These attributes represent the most previously investigated functional stimuli: 'Spatial layout'. On the other hand, 'nature' is classified as the major researched sensorial stimulus, while 'light' comes as a second priority. 


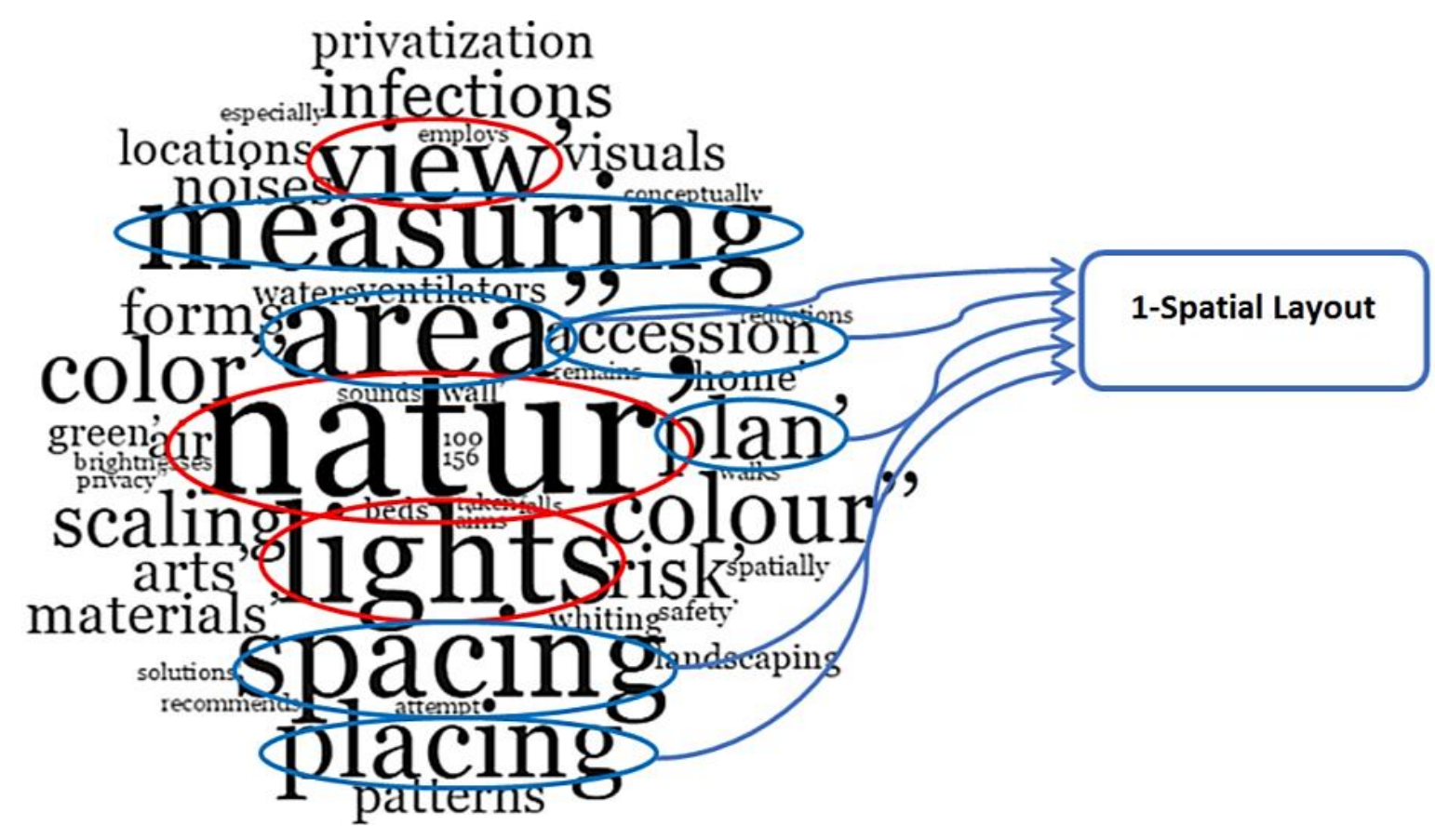

Figure 3. Word cloud of the final review analysis

\section{Characteristics of the 15 PSDS}

The second part of this paper is meant to identify the main characteristics of the fifteen resulted PSDS, in relation to creating positive mental procedures and promoting positive connections with the spatial environment, as defined through the review analysis.

\subsection{Functional Stimuli:}

\subsubsection{Spatial layout}

'Spatial layout' is found as the major psychological stimulus influencing users' psychology at public buildings. The efficient distribution and relationships between different buildings' zones is considered as the main aspect of this stimulus. Availability of spaces is another most common factor influencing users' psychological wellbeing (Browning et al. 2014). It is important to have multi-purpose spaces that could be used for meetings, gatherings, or confidential discussions (Sheldon et al. 2009b). Spatial hierarchy, access, and circulation, are other features that directly affect users' psychology. The analysis revealed the significance of zones' hierarchy and reasonable sizes, wayfinding aid to simplify users' journeys, segregation between different users' types. A study done by Sheldon et al. (2009a), on healthcare premises, shows that both staff and patients identified problems with large and disconnected spaces: staff perceived the unfavourable effect on communication and 
patients perceived the difficulties with movement through these spaces. Design strategies such as double-height spaces, semi-outdoor paths or external reference spaces can be adopted to identify boundaries between different zones and facilitate navigation. Literature stressed that human scale zones with a friendly, up-to-date and environmentally sustainable setting should be embraced in any building typology. This includes bright airy spaces, easy to use for those with mobility restrictions (Department of Health 2013a). For instance; in a supportive environment for working staff, rest rooms should provide good-quality environments that promote positive interaction. According to Karlin and Zeiss (2006), staff lounges could improve morale, job satisfaction and encourage professional communication. However, the study shows that those areas (kitchen/dining and lounge/relaxation) receive less attention in the design of healthcare buildings.

Public zones such as public entrances, receptions, waiting areas, public toilets and information points, should promote a sense of 'community ownership', safety and confidentiality for all age groups. For instance, elderly and disable design consideration should be a priority, as well, providing safe and secured play areas for children to play without disturbing adults, should be priorities in the design of any communal buildings.

Research show that the predominant practice of arranging seating side-by-side, constrains social interaction; contrarily, there is strong evidence that levels of social interaction can be increased through providing comfortable movable furniture arranged in small clusters (Peterson et al. 1977; Melin \& Gotestam 1981; Ulrich et al. 2008). Private discussion enclosure near waiting areas can reduce stresses arising from breaches of speech privacy in healthcare buildings (Ulrich et al. 2008). Many studies stressed the importance of wayfinding within healthcare buildings; orientation aids, such as signage, information desks, and maps. Scholars found that patients who experience efficient wayfinding system feel more self-contained, independent and put less stress on healthcare staff (Pati, Harvey, Willis \& Pati 2015; Devlin 2014)

\subsubsection{Ergonomics}

Ergonomic is the design of spaces and equipment to maximize performance and physical wellbeing to minimize fatigue, dullness and accidents (Hewstone et al. 2005). Poor ergonomic design can lead to back pain, fatigue, and other physical harms amongst users 
which directly affect their psychological wellbeing, being unsafe and prone to injuries. Improving ergonomics in any setting means improving satisfaction, increased comfort, decreased physical strains (Nevala \& Tamminen-Peter 2004; Springer 2007).

Space size is one of the most occurring topics in the review analysis that influences users' wellbeing (Browning et al. 2014). A study done by Sheldon et al. (2009b) shows that ergonomics was the main priority for staff in GP buildings; as space size affect the spatial distribution and limit their performance. Designers are entailed to work collaboratively with space-users on delivering quality ergonomics from early design stages (Price and Lu 2012).

\subsubsection{Privacy}

Privacy is important for individual/community well-being and quality of life. It is an area of significance in architectural psychology. Privacy is associated with the control over the immediate environment; including the ability to organise and personalise one's space. Thus, privacy adjustments could be established through physical or psychological barriers; wherever individuals seek protection. Sound and visual privacy are the common functions of refuge environments. The capability to flexibly regulate social interaction is a major contributor to the sense of control over spatial settings (Sundstrom, Town, Rice, Osborn, \& Brill 1994; Browning et al. 2014). Within any built-environment, users' privacy level [depending on the building's function] is meant to affect mental processes, consequently regulates ones' psychological interactions; e.g. overcrowded workplaces are associated with stresses and job dissatisfaction (Burke 1988; Fairbrother and Warn 2003). Separation of patient and staff areas in healthcare settings, especially areas for relaxation and facilities, is a major factor affecting staff satisfaction. Department of Health (2013a) stresses that separate gender staff changing and showering areas, as well as, separate staff toilets should be provided in all healthcare settings regardless of their size. Pleasant staff private zone that provides the privacy of staff from patients, like private relaxation areas, communal social areas, kitchen/dining of sufficient size as needed; was seen of major importance in healthcare settings to enhance work efficiency and facilitate effective communication (Sheldon et al. 2009b). 


\subsubsection{Furniture}

Not many studies investigated furniture in relation to users' satisfaction. Some research proved robust impact of furniture type, materials, style, distribution, etc. on users' psychology. In healthcare settings, fixed furniture was described as a problem in consultation rooms (Sheldon et al. 2009b). The Department of Health (2013a) recommends mobile, rather than fixed, equipment and furniture. Moveable furniture were found to encourage interaction, provision of comfortable interpersonal distances, eye contact, and physical comfort during the conversation (Flischl 2006). Natalija Subotincic (1999a \& 1999b) analysed Sigmund Freud's office about his theories; including the study of physical dimensions of his consultation room, furniture arrangement, and Freud's large collection of antiquities. The study argues that furniture is the face-to-face therapist of clients; which raises triggering questions regarding intimidating seating arrangement, available choices of furniture distribution, types of furniture and their influence on clients' emotional control, or enhancing good feelings (Bonnes and Bonaiuto 2002).

Malone and Dellinger (2011), from the Centre for Health Design, suggested a 'furniture design checklist' in healthcare settings that could be adapted to other settings, which includes; decreasing stress and fatigue (e.g. safe and comfortable furniture), improve effectiveness and communication, adjustable to individual ergonomics, and improve environmental safety (e.g. do not contain harmful chemicals) (Salonen et al. 2013a). Additionally, grouped separated-seats, instead of fixed furniture were recommended for waiting areas in a healthcare setting. While, old, worn, and uncomfortable furniture were amongst the most negative influencing stimuli in healthcare facilities (Dijkstra et al. 2006).

Some research on offices found a positive correlation between space personalization and mental wellbeing within the work environment (Fairbrother and Warn 2003); where employees may decorate their workspace with personal gadgets like photos, memorabilia, artwork, plants, and other unique objects-as allowed by company policies and features of the workspace.

\subsubsection{Safety \& Infection-control}

Promoting personal safety is always associated with reducing stress. Many studies connected feelings of unsafety to dealing with difficult/dangerous passages (Bixler \& Floyd 
1997), lack of orientation (Kaplan \& Kaplan 1989), or the danger of molestation or robbery, especially among women (Cinar \& Cubukcu 2012). Heerwagen (2009) argues that some movement patterns may be associated with safety and tranquillity, while others indicate danger; movement associated with safety is of a soft pattern that always changes, yet remains the same (e.g. the movement of trees or grasses in a light breeze, aquarium fish, or the pattern of light and shade created by cumulus clouds).

The sense of safety increases the feeling of place attachment; attached individuals experience a heightened sense of safety, even if situated in a war zone (Scannell and Gifford 2010). A strong sense of community is associated feelings of safety and security (Francis et al. 2012), where physical environment along with social support, organizational culture, and technology can play an important role in improving health, safety, effectiveness and satisfaction.

Sheldon et al. (2009a) found that patients' safety was best served by a single waiting space that is visible from reception, where staff placed importance on safety at reception through the provision of wide reception desks. Where also safety and security included the exterior of the building, with no 'hiding' places (blind spots). The same research highlighted other aspects of staff safety and security; such as fire escape, management of users' behaviour, limiting working in isolated zones (especially at night), reception desk of sufficient height and width to protect staff from attack, good natural light, temperature control, and good ventilation. Other researches recommended the use of materials free of harmful chemicals for environmental safety (Malone and Dellinger 2011; and Salonen et al. 2013a)

Several obligations are set out in legislation, including the Health and Safety at Work Act 1974 , that establish a general duty on employers to ensure the health, safety and welfare at work of all their employees (Department of Health 2013b).

Interactions with features of the physical work environment may be evaluated according to levels of arousal, adaptation, fatigue, stress, safety, and security (Bonnes and Bonaiuto 2002). 


\subsection{Sensorial Stimuli}

\subsubsection{Nature}

Natural scenes are generally defined as the absence of artefacts, but not necessarily lack human management. Human intuition and neural sciences show that connections to nature are vital to maintaining a healthful and vibrant existence as urban species.

A survey on more than 4000 members of the American Horticultural Society showed that over $80 \%$ indicated peacefulness and tranquillity as the most important feelings during interaction with nature. It was also found that nature reduces negative feelings such as anger, fear, aggression, or arousal, and increased overall positive effects such as happiness, and friendliness (Hartig et al. 1991 \& 1996; Ulrich et al. 1991). Visual Connection with nature was proved to lower blood pressure and heart rate (Brown, Barton \& Gladwell 2013; Van Den Berg, Hartig, \& Staats 2007), while on the cognitive performance level, it improved mental engagement/attentiveness (Browning et al. 2014).

Researches proved that adults, in general, tend to consider scenes as natural under three conditions: (1) if the landscape is dominated by vegetation, water, or mountains; (2) if artificial features are absent or concealed; and (3) if the dominant contours or visual profiles are curvilinear or irregular rather than rectilinear or regular (Ulrich, 1983 \& 1993; Wohlwill 1983). Examples of natural scenes include parks and open spaces, street trees, vacant lots, back yards, fields, forests (Kaplan et al. 1989), pastures, cereal crops, and golf courses (Ulrich 1993; Han 2003).

Recent research body supports measurable positive impacts of biophilic design on health, strengthening the empirical evidence for the human-nature connection and raising its priority level within both design research and design practice. However, little guidance for implementation exists; where it was realised that spatial connections to natural areas such as small gardens and seating area in interior courtyards adjacent to functional rooms, can significantly reduce stress (Browning et al. 2014).

\subsubsection{Views}

Recent studies proved that nature scenery stimulates a larger portion of visual cortex than non-nature sight, which triggers more brain's pleasure receptors, leading to prolonged interest and faster stress recover. Viewing nature for ten minutes before experiencing a 
mental stressor has shown to stimulate heart rate variability and parasympathetic activity (Brown, Barton \& Gladwell 2013) while viewing a forest scene for 20 minutes after a mental stressor has shown to return cerebral blood flow and brain activity to a relaxed state (Tsunetsugu, Miyazaki \& Sato 2005). Yet, repeated viewing of real nature, unlike nonnature, does not reduce viewers' level of interest over time (Biederman \& vessel 2006).

In office design, according to Browning et al. (2014), a view of nature has a restorative and healing effect and encompasses four biophilic design attributes: 1) Prospect ${ }^{1}$; 2) Refuge ${ }^{2}$; 3) Mystery ${ }^{3}$; and 4) Risk/Peril ${ }^{4}$. While Moore (1982) found that prisoners whose windows looked out to nearby nature reported fewer sick calls than those whose window looked out to buildings. Hence, Ulrich et al. (2008) emphasise that attention should be given to opening towards nature-view in procedure spaces, treatment rooms, and waiting areas where pain is a problem.

\subsubsection{Light}

The human body responds to daylight colour transition; where sunlight changes colour from yellow in the morning, to blue at midday, and red in the afternoon/evening. The response is apparent in body temperature, heart-rate, and circadian functioning. Higher content of blue light (similar to skylight) produces serotonin; whereas, its absence produces melatonin. The balance of serotonin and melatonin can be linked to sleep quality, mood, alertness, depression, breast cancer and other health conditions (Kandel et al. 2013).

A large body of rigorous evidence indicates that exposure to bright artificial light and daylight is effective in reducing depression and improving mood. Research on school children showed that quality daylighting induces more positive moods and significant less dental decay amongst students, being directly linked to the absorption of vitamin $D$ (Nicklas \& Bailey 1996). Poor lighting levels can affect the performance of healthcare workers and lead to medical errors (Buchanan et al. 1991). Dynamic and diffused light has an impact on stress reduction as it is positively impacted circadian system functioning; this relates to

\footnotetext{
${ }^{1}$ An unimpeded view over a distance for surveillance and planning

${ }^{2}$ A place for withdrawal from environmental conditions or the main flow of activity, in which the individual is protected from behind and overhead

${ }^{3}$ The promise of more information, achieved through partially obscured views or other sensory devices that entice the individual to travel deeper into the environment

${ }^{4}$ An identifiable threat coupled with a reliable safeguard
} 
leverages varying intensities of light and shadow that change over time to create conditions that occur in nature (Figueiro et al. 2011). The objective of the Dynamic \& Diffuse Light pattern is two-fold: to provide users with lighting options that stimulate the eye and hold attention in a manner that engenders a positive psychological or physiological response and to help maintain circadian system functioning. Hence, it is recommended that façades and internal layouts should be designed to enhance daylight and light/shade variability while reducing glare.

\subsubsection{Colours}

Colours are of significant importance for creating wellbeing-supportive environments. The term 'colour-psychology' often reflects the psychological effects of colour; it refers to a range of affective, cognitive, and behavioural responses and associations linked to specific colours; including effect, preference, and cognitive judgements. In turn, those are often combined with biological and behavioural responses to colour (Van Wagner 2009). Some reviews extend this definition to cover a further range of attributes such as colourpreference, pre-cognitive and biology-based attributes. Kopacz (2004 p.92) suggests that the "biological consequences of colour responses can be a valuable tool in health management" to treat various sicknesses; moreover, colour-therapy, or Chroma-therapy, can be used as a holistic, non-invasive, and powerful therapy.

Most colour preferences preceding studies suggest that link between colour and human response is common regardless of individuality or cultural differences (O'Connor 2011). However, recent studies found that human responses to colours may vary depending on age, gender, culture, and preference; hence, it is subjective. Therefore, when colour harmony studies are combined with the science of psychology, reactions can be predicted with surprising accuracy.

On the other hand, colour-healing research suggests that colours can be used as a physiological treatment tool. For example, the red colour activates the circulation system and benefits the five senses; blue raises metabolism, stabilises the heart, muscles and bloodstream; green strengthens bones and muscles, disinfects bacteria and virus, and relieves tension (Kopacz 2004). 
To inspect colour psychological preferences, many studies developed tests or systems to examine how colours work; for example, the "Lüscher Color Test", by which Lüscher (1990) referred to subjective evidence, assigned specific associations and affective characteristics to each colour. Similarly, the "The Colour Affects System" established by Angela Wright, in the late 1970s/early 1980s, identified four colour families corresponding to four basic personality types, within which every colour naturally harmonises with every other colour in the family; stressing that colours from different families do not harmonise. Wright based her theory on studying the Freudian psychology and the dynamics of colour, to declare that each hue affects distinct psychological modes, all humanity can be classified into one of four personality types, each personality type has a natural affinity with one colour group and that response to colour schemes is influenced by personality type (Ou et al. 2004). Furthermore, "The Manchester Colour Wheel" [MCW] was developed in response to the need of creating a simple, reliable and validated method for allowing a choice of colour in response to a series of psychological and emotional questions. This colour wheel is used to assess psychological status, mood or even treatment outcome in a variety of clinical situations (Carruthers et al. 2010).

Art and architectural design are commonly associated with the experience of space, colours and form. In nature, colour is expressed throughout the animal and plant kingdoms as a form of communication and survival, whereas humans respond to colour imagery on a deeper level, which proposes a subliminal activity (Duncan 2011). Within architecture, it would therefore be interesting to verify whether differences in colour warmth can be found for different building elements, like floors, walls and ceilings. Comparing the effect of material and colour; colour has a greater impact on warmth than the other material aspects. Applying colour to material could be a more effective way to modify the perception of warmth than changing the surface roughness or gloss. Moreover, all colours, except the steel-grey, are perceived as warmer than the white coloured plaster sample. A white wall can be considered the most neutral wall element in architecture; it also seems to lead to the coldest perception (Wastiels et al. 2012).

At healthcare environments, colours have a major effect on the healing process and users' wellbeing. However, cost, maintenance and storage of paint materials are important issues related to colour. Sometimes this can lead to a single colour dominating the environment, 
such as blue, which in many cases creates a heavy institutional feeling. Yet, colour divergence can form an obstacle that is difficult to be tolerated. Features of a building that creates tonal detail or shadows can also aid visually impaired users. While, well-designed, ambient environments should have transitions of lighting and colour design that permit eyes to adapt to changes in lighting levels (Dalke et al. 2006). For instance, the preferred colour schemes at healthcare buildings, McCullough (2009) recommended various shades of soft gold, warm beiges, and accents of spice and warm brown, while Flischl (2006) recommends a variation between light white and yellow/orange, warm red, and beige, and calm green, cream, terracotta, brown.

Finally, many research findings suggest that colours influence human response, the presence of an indisputable and universal causal link between colour and an unlimited range of psychological, biological, and behavioural responses. Other studies assert that there are no 'hard-wired' connections between environmental colours and particular emotional states. Furthermore, the findings of many studies are also limited because of the methodological weakness of studying a complex and subjective phenomenon such as colour in isolation.

\subsubsection{Artwork}

The artwork is a very human object, done by a human being for others to enjoy. It has, therefore, an innate wonder and warmth (McCullough 2009). Nowadays, art is considered an essential component of healing spaces that improve the indoor environment (Salonen et al. 2013a). Art in its various forms: paintings, sculptures, photography, etc., is an evident positive distraction in healthcare settings for patients and staff (McCullough 2009). Colours, textures, intensities, degree of abstraction, and subject matter of artwork inspire and support patients' response to the healing process (Bonnes and Bonaiuto 2002; Han 2003).

The review analysis shows that patients steadily preferred images of nature and reacted negatively to chaotic, non-representational, abstract art (Ulrich \& Gilpin 2003). Pictures of nature and other emotionally appropriate artwork provoke positive reactions, while research showed that some art styles could cause negative emotions and increase the stress level. For instance, the appropriateness of the abstract art could be questioned in healthcare settings; displaying emotionally challenging art in healthcare environments cause 
strongly negative reactions. Artworks that were ambiguous, surreal, or could hold multiple interpretations, are perceived by healthcare users of significant negative impact on their wellbeing, as revealed by Ulrich (1991). The consensus is that abstract art can be used, yet it may be considered for circulation areas rather than for patients' care and waiting spaces (McCullough 2009). Further study indicated that patients are significantly more positive about paintings of landscapes with verdant foliage, flowers, and water than to best-selling artwork even by masters such as Chagall and Van Gogh (Nanda et al. 2007).

Designers can also use art to establish and reinforce a sense of place. For example, the art program at New Hanover Regional Medical Centre, North Carolina, was based on the theme of 'cosy beach house'. This was created by photos of local landscapes (beaches, marshes, gardens, the ocean, etc.), floral (close-ups of gardens), and local birds (egrets, ducks, swans, etc.). A donation made for art in the chapel allowed for the commissioning of a beautifully curved metal sculpture depicting the beach and a lighthouse (McCullough 2009).

Certain types of psychologically appropriate artwork, including representational images with themes relating to waterscapes, natural landscapes, flowers, and gardens, and figurative art with emotionally positive gestures and facial expressions, proved to have various medical outcomes; e.g. reducing blood pressure, heart rate, pain and anxiety. As well as, psychological outcomes; e.g. reducing stress. A study indicated that patients viewing even a colour picture with a well-lighted view of trees and water needed fewer doses of strong painkiller drugs (Ulrich et al. 1991).

McCullough (2009) suggests creating art niches built into walls to incorporate art, in its different types, as a positive distraction and add depth to the interior space. Scholars also recommended that if human-shaped figures are used, they better be ambiguous. For example, a painting of a woman with long flowing hair could be disappointing to a cancer patient.

\subsubsection{Finishing Materials \& Textures}

Building materials and textures form affect users' perceptions and contribute in shaping their spatial experiences; hence, they give the building its identity and highlight its purpose and nature. Building's exposed materials indicate how cold or warm it feels. Materials with low-temperature resistance, such as glass and metal, feel cold. Metal feels colder than 
wood, even when both are at similar room's temperature. Yet, a brick at freezing temperature feels colder than a brick at room temperature. Personal memory and associations also shape users' psychological feelings about buildings' materials. A study by Wastiels et al. (2012) revealed a strong connotation between the experience of warmth, material's colour/shade and its surface gloss. Thii-Evensen's (1987) proved that glossy materials lead to colder spaces than textured materials. The study showed a negative correlation between the gloss ${ }^{5}$ texture and the feeling of warmth (Thiis-Evensen 1987; Wastiels et al. 2012). There is a positive correlation between the perception of warmth and the roughness of the surface of the material; as rough surfaces absorb more light than smooth surfaces (ibid).

However, the functionality of the used materials in relation to its surrounding context, play an important role in how users perceive it and feel it. Healthcare buildings' finishing materials have a strong impact on patients' wellbeing and comfort. Studies demonstrate that porous materials enable larger amounts of dust to be accumulated than smooth materials. Spaces with high activities in care buildings are entailed to re-emit more dust if rough materials are used than sleek ones, such as hard floors versus carpets. Additionally, carpets in care buildings are difficult for staff to push carts, gurneys and wheelchairs, which is associated with increased risk of neck, shoulder and lower back pain. Counter research showed that carpets performed well in cleaning, and certain serious pathogens survive for less time on carpets than on other floor coverings (Lankford et al. 2006). Other studies reported psychological and physiological comfort using carpets, including noise reduction, glare reduction, ease of walking, reduction of injuries from falls, improved personal comfort and thermal comfort, longer visits by family and friends, increased social support and creating a homelike (non-institutional) ambience (Ulrich et al. 2004).

Natural materials when used efficiently feels rich, warm, authentic; as it provides a feeling of connection with nature, sometimes stimulating to the touch. A study proved that a room with a $45 \%$ coverage of wood material evoked increased comfortable feeling, exhibited a significant decrease in diastolic blood pressure and significant increases in pulse rate. While a decline in brain activity was reported in higher wood coverage (90\%), which is either

\footnotetext{
${ }^{5}$ Gloss is defined as a visual parameter describing a material's behaviour in response to incident light.
} 
restorative as in spas or doctors' offices or counter-productive if in a space where high cognitive functionality is expected (Tsunetsugu, Miyazaki \& Sato 2005).

Dilani (2009) recommends enhancing the sensory appeal by using pleasing materials' tactile to increase people's experience of the healthcare environment. In addition, it is advised to maximise the use of natural materials wherever possible (Grant 2011; Hahn 2012) (Gesler et al. 2004; Heerwagen 2009). The use of moderate textured and accent details made of natural materials such as wood-alike materials, oak, stone, pine, wood grains, leather, stone, fossil textures, bamboo, rattan, dried grasses, cork, etc. is highly recommended; while real materials are preferred over synthetic variations (Krebs 1985; Heerwagen 2009). Variation in materials on the floor can create pathways and help people move around a busy space in a more organised manner (HBN:11-01 2013). Domestic-style materials, finishes and décor help patients relax and feel more at ease, in healthcare settings.

In general, the efficient choice of materials during prime design phases could greatly affect/enhance users' psychological experience in the building. Materials and finishes should be designated to be compatible with rooms intended function, minimise maintenance and cleaning, especially where contamination is a possibility (HBN:11-01 2013).

\subsubsection{Sounds}

Noise is a persistent environmental stressor that augments psychological and physiological stress. Ulrich et al. (1991) identified three major sources of noise in built environment: 1) internal sources ${ }^{6}$; 2) poor acoustic conditions ${ }^{7}$; and 3) external sources ${ }^{8}$.

According to Weber's law, the sound stimulus establishes a fair noticeable difference when it is a constant proportion of the intensity of the initial contextual sound stimulus. Weber's law proved that the proportion of fair noticeable difference is 1:50 from the initial contextual sound (Feldman 2011). In general, noise as loud as 90dBA lowers performance of complex technical tasks, attention \& mental tasks, and dual tasks. In addition, working in a noisy environment correlates with physiological symptoms of stress, such as; elevated heart rates, chronic headaches. One's health suffers more through prolonged exposure to noise,

\footnotetext{
${ }^{6}$ E.g. talking users, children, phones or system beeper, sounds of equipment

${ }^{7}$ Enabling sounds to echo and reflect from surfaces such as floors, ceilings, or walls that are not soundabsorbent

${ }^{8}$ E.g. rain on windows and roofs, traffic, disturbances on the street and neighbouring schools
} 
especially when combined with an additional source of job stress (Evans et al. 1994). Noise often has continuing long-term effects on performance and stress. Although the noise may not directly hinder staff performance, the cumulative effects of stress may lead to adverse outcomes (Ulrich et al. 1991). Blue-collar workers exposed to moderately elevated noise levels at work show little or no ill health effects unless they have been exposed for many years (Talbott et al. 1990; Winkel et al. 2009)

Literature shows that exposure to nature's sounds accelerates physiological and psychological restoration, after a psychological stressor, up to $37 \%$ faster when compared to urban or office noise (Alvarsson et al. 2010; Jahncke et al. 2011; Browning et al. 2014). Three themes formed the basis of these perceived relationships: affective appraisals, cognitive appraisals, and relationships with nature. Other sub-themes such as the acoustic, aesthetic, and accompanying properties of bird sounds were also related to restorative perceptions (Ratcliffe et al. 2013). Browning et al. (2014) showed that participants who either listened to river sounds or saw a nature movie with river sounds in post-task restoration period reported greater motivation and more energy compared to participants who only listened to office noise or silence. In addition, the view of nature with river sounds had a more positive effect than only listening to river sounds alone.

Several studies show that controllable pleasant music assists patients in coping with pain, lowers blood pressure, decreases anxiety and depression, decreases heart rate, decreases respiratory rate, brings a higher level of satisfaction with the experience, improves memory, decreases behavioural problems and over-excitement, reduces severe postoperative confusion and delirium, improves coping abilities and speeds up recovery. A set of research results indicate that listening to Mozart's music may induce a short-term improvement on the performance of certain kinds of mental tasks known as "spatial-temporal reasoning" this phenomenon is called by "Mozart effect"9 (Salonen et al. 2013b). Yet, many published studies found no effect of music on performance at workplaces; however, employees found

\footnotetext{
${ }^{9}$ The "Mozart effect" is the popular idea that "listening to Mozart makes you smarter", or that early childhood exposure to classical music has a beneficial effect on mental development.
} 
music positive and favourable. Allen and Blascovich (1994), reported that surgeons achieved better when listening to the music of their choice.

\subsubsection{Shapes \& Patterns}

Visual stimuli of a particular shape or pattern are similar to landmarks in space; they are distinctive and instantly caught and interpreted by our brains; this process is known as feature detection (Feldman 2011). Recent neuroscience evidence shows that our visual system processes object properties such as shape and colour in order to identify this object (Kozhevnikov 2007); our sensory neurons are detectors that respond to particular features of a stimulus, such as its shape, angle, or colour (Passer and Smith 2012).

Virtuous patterns are expected to be simple. Without a pattern, our view of the surrounding would be vaguer and equivocal. Within specific architectural styles, patterns were associated with robust ornamentation and excessive decoration. However, patterns should not be confused with ornaments (Liotta et al. 2012).

A study from the field of environmental psychology and aesthetics showed that contact with natural/organic shapes is good for human psychological and physiological functioning. It is strongly argued that these beneficial effects can be expressed in a built context by architecturally mimicking natural patterns and structural associations of natural settings; e.g. arches, vaults, dome and other shapes resisting straight lines, right angles are highly recommended over straight and sharp shapes and angles (Joye 2007).

Hahn (2012) recommends information-richness of patterns in design, such as; age changes and the patina of time, growth, central focal point, patterned wholes, chains and linked series, integration of parts to wholes, complementary contrasts, dynamic balance and tension, hierarchically organised scales, etc. Biomorphic patterns \& forms could be presented by symbolic references to natural textures and patterns with numerical arrangements that persist in nature; such as the Fibonacci sequence $\&$ the golden ration (Joye 2007).

Curvy shapes and geometry always draw users' attention and create a feeling of comfort (Lynn 1999). Empirical studies proved that curved shapes are perceived to create a relaxed 
and warm atmosphere, more homely and less institutional-like space (Curtis et al. 2007). In the workplace, regular geometric shapes can attract attention, sharpening visual memory in relevance to direction and orientation. A study on elderly residents with dementia showed that they developed negative associations with natural stimuli, while, coloured cardboard with geometric shapes placed near exits (doors and stairways) had a great impact on improving their spatial orientation, walking less bearing those images (Hussian 1982; Day et al. 2000).

In general, patterns are a means to achieve contrast between materials and colours through the pattern shape; for instance convex-concave; pattern direction such as in zigzags (Salingaros 1995).

\subsubsection{Natural Ventilation \& Thermal Comfort}

Thermal comfort is linked to ambient air temperature, relative humidity, radiant heat sources, air movement, activity level, wearing, and individual differences. Research from social psychology found a correlation between uncomfortable high temperature and aggressive behaviour. Exposure to heat for 30 minutes or more without rest periods lowers performance of complex, demanding and dual tasks, proposing that heat contributes to sensory cognitive overload and stimulates coping responses like lessening attention and ignoring involvements with less-priority.

At healthcare buildings, the direction of airflow and air pressure, air exchanges per hour in the room, humidity, and ventilation system cleaning and maintenance are linked to air quality and infection rates (McDonald et al. 1998; Lutz 2003; Ulrich et al. 2004).

Temperature is one of the common causes of staff dissatisfaction in any workplace (Ulrich et al. 2004). Studies on workplaces found adverse effects of heat on output and accident rates improved by ventilation (Fairbrother and Warn 2003). The main attributes related to air quality that affect staff wellbeing in workplaces embrace mainly ventilation and air pollution; this includes flow of fresh air, humidity, dust, gas, or other ingredients than natural elements of air. According to Sheldon et al. (2009b), decent temperature, thermal control, good insulation and effective heating/cooling systems contribute directly to staff wellbeing. On the other hand, a psychological study found that ambient temperature is positively connected to workload burdens (Fairbrother and Warn 2003). 
It is important for users to be able to control thermal conditions, either by using individual controls or allowing occupants' access to variable ambient conditions within a space (Sheldon et al. 2009b).

In order to achieve the optimum thermal comfort, Andrade et al. (2012) advise avoiding inadequate temperature (e.g. too hot or too cold). The air exchange should be sufficient with convenient air humidity level. Natural and Mechanical ventilation should limit the diffusion of bad odours (Estates 2010). There is a growing need to examine the different types of ventilation systems, a fraction of re-circulated air, air cleaning and filtration technologies, and humidification, as well as, the disinfection processes of HVAC systems (Sundell et al. 2011). Other design strategies such as; increasing natural airflow to help to avoid sick building syndrome; augmenting day-light to help cut energy costs in terms of heating and cooling; increased vegetation to help air purification, reduce urban heat island effect, improve air infiltration rates and reduce perceived noise levels, should be implemented (Forsyth \& Musacchio 2005).

\subsubsection{Water}

Many studies proved that the manifestation of water feature in space reduces stress and increases the feelings of tranquillity by lowering heart rate and blood pressure (Biederman \& vessel 2006; Wiens \& Nilsson 2010; Watts 2010). Water features help improving concentration and memory restoration, awareness and psychological responsiveness (Biederman \& vessel 2006; Alvarsson et al. 2010; Hunter et al. 2010; Alvarsson et al. 2010; Browning et al. 2014). A visual preference study indicates that the view of clean water represented a preferred view to all participants (Heerwagen \& Orians 1993).

The objective of water presence is to take advantage of its multisensory attributes to enhance a comforting place experience, stimulate meditation, enhance mood, and provide restoration from cognitive fatigue. Constant experiences of water do not considerably reduce levels of interest over time. Taking advantage of sounds created by small-scale running water, and user's capacity to touch it strengthens a multisensory experience. Vistas to extended water surfaces or physical access to natural or designed water areas can also have the same impact as long as they are perceived as 'clean' or unpolluted (Ulrich et al. 2008; Solli and Lenz 2011). 


\section{Conclusion}

The listed above spatial attributes are found through the analysed review to have the most influential impact on ones' psychology within the spatial environment. it is important to note that these stimuli, if well employed in the design, are meant to create a 'positive distraction' for the mind and enhance users' wellbeing. These spatial distractions assist in altering a person's frame of mind and play a key role in creating a positive psychological experience. (McCullough 2009).

Literature focused on the relative contribution of environmental factors to emotional and cognitive responses (Schreuder et al. 2016). Recent developments in healthcare design highlighted the importance of "humanising" healthcare contexts by focusing on a set of design attributes in order to satisfy fundamental users' needs. However, it is important to highlight that the intensity and characteristics these spatial stimuli are employed in the design vary widely depending on the function and nature of the building's users. Berlyne's (1960) optimal arousal theory may provide a possible explanation to these findings; the theory suggests that the relation between an individual's level of arousal and affective state of mind, created by any stimulus, can be represented by a bell-shaped function. Individuals usually prefer medium levels of arousal. Stimuli causing extreme levels of arousal result in negative emotional impact.

Literature review on emotional effects of multisensory stimulation, and how interventions in the environment may elicit desired responses, shows that evidence on multisensory effects is still scarce and disorganised. The evidence stems from research has considerable variations depending on the experimental conditions, methodologies, and measures used. This makes it hard to relate findings from different studies in a single perspective. Although interesting mechanisms have been identified, and some promising theses can be formulated using the presented framework and its background, there is yet insufficient evidence to validate a type of framework as postulated here. Consequently, the ability to formulate multisensory assumptions on effective interventions is yet only hypothetic. 


\section{References}

Allen, K., and Blascovich, J. (1994). Effects of music on cardiovascular reactivity among surgeons. JAMA: Journal of the American Medical Association, 272(11), 882-884. https://doi.org/10.1001/jama.1994.03520110062030

Andrade, C., Lima, M. L., Fornara, F. and Bonaiuto, M. (2012). Users' views of hospital environmental quality: Validation of the Perceived Hospital Environment Quality Indicators (PHEQIs). Journal of Environmental Psychology, 32, 97-111. https://doi.org/10.1016/j.jenvp.2011.12.001

Biederman, I. and Vessel, E. A. (2006). Perceptual Pleasure and the Brain: A novel theory explains why the brain craves information and seeks it through the senses. American Scientist, 94(3), 247-253. https://www.jstor.org/stable/27858773

Bixler, R. D. and Floyd, M. F. (1997). Nature is Scary, Disgusting, and Uncomfortable. Environment and Behavior, 29(4), 443-467. https://doi.org/10.1177/001391659702900401

Bonnese, M. and Bonaiuto, M. (2002). Environmental psychology: From spatial-physical environment to sustainable development. In Bechtel, R. B., and Churchman, A. (Eds.) Handbook of environmental psychology, 28-54. John Wiley and Sons Inc., New York, USA.

Brown, D.K., Barton, J.L., and Gladwell, V.F. (2013). Viewing Nature Scenes Positively Affects Recovery of Autonomic Function Following Acute-Mental Stress. Environmental science \& technology.

Browning, W., Ryan, C. and Clancy, J. (2014). 14 patterns of biophilic design: Improving Health \& Well-Being in the Built Environment. Terrapin Bright Green Ilc., New York, USA.

Buchanan, T. L., Barker, K. N., Gibson, J. T., Jiang, B. C., and Pearson, R. E. (1991). Illumination and errors in dispensing. American Journal of Hospital Pharmacy. 48(10), 2137-45. PMID: 1781468

Carruthers, H. R., Morris, J., Tarrier, N. and Whorwell, P. J. (2010). The Manchester Color Wheel: development of a novel way of identifying color choice and its validation in healthy, anxious and depressed individuals. BMC medical research methodology, 10, 12. https:// doi.org/10.1186/1471-2288-10-12 
Cinar, E. A. and Cubukcu, E. (2012). The Influence of Micro Scale Environmental Characteristics on Crime and Fear. Procedia - Social and Behavioral Sciences, 35, 83-88. https://doi.org/10.1016/j.sbspro.2012.02.065

Curtis, S., Gesler, W., Fabian, K., Francis, S. and Priebe, S. (2007). Therapeutic landscapes in hospital design: a qualitative assessment by staff and service users of the design of a new mental health inpatient unit. Environment and Planning C: Politics and Space, 25(4), 591610. https://doi.org/10.1068/c1312r

Dalke, H., Little, J., Niemann, E., Camgoz, N., Steadman, G., Hill, S. and Stott, L. (2006). Colour and lighting in hospital design. Optics \& Laser Technology, 38(4-6), 343-365. https://doi.org/10.1016/j.optlastec.2005.06.040

Day, K., Carreon, D. and Stump, C. (2000). The therapeutic design of environments for people with dementia a review of the empirical research. The Gerontologist, 40, 397-416. https://doi.org/10.1093/geront/40.4.397

Department of Health (2013a). Health Building Note 11-01: Facilities for primary and community care services. London, England.

Department of Health (2013b). DH Health building notes. Health Building Note 11-01: Supplement $A$ - Resilience and emergency planning in primary and community care. London, England.

Devlin, A. S. (2014). Wayfinding in Healthcare Facilities: Contributions from Environmental Psychology. Behavioral Sciences, 4(4), 423-436. https://doi.org/10.3390/bs4040423

Dijkstra, K., Pieterse, M. and Pruyn, A. (2006). Physical environmental stimuli that turn healthcare facilities into healing environments through psychologically mediated effects: systematic review. Journal of Advanced Nursing, 56(2), 166-181. https://doi.org/10.1111/j.1365-2648.2006.03990.x

Dilani, A. (2009). Psychosocially Supportive Design: A Salutogenic Approach to the Design of the Physical Environment. SHB2009: 1st International Conference on Sustainable Healthy Buildings. Seoul, Korea.

Duncan, J. (2011). The effect of colour and design in labour and delivery: A scientific approach. Optics \& Laser Technology, 43(2), 420-424. https://doi.org/10.1016/j.optlastec.2010.02.008

Estates, N. (2010). HBN 12 Out-patients department. DH Department of Health, Leeds, England. 
Fairbrother, K. and Warn, J. (2003). Workplace dimensions, stress and job satisfaction. Journal of managerial psychology, 18(1), 8-21. https://doi.org/10.1108/02683940310459565

Feldman, R. S. (2011). Understanding Psychology. McGraw-Hill, New York, USA.

Figueiro, M. G. Brons, J. A., Plitnick, B., Donlan, B., Leslie, R. P. and Rea, M. S. (2011). Measuring circadian light and its impact on adolescents. Light Res Technol, 43(2), 201215. https://doi.org/10.1177/1477153510382853

Fiischl, G. (2006). Psychosocially supportive design in the indoor environment. PhD thesis, Luleå University of Technology, Luleå, Sweden.

Forsyth, A. and Musacchio, L. R. (2005). Designing Small Parks: A Manual for Addressing Social and Ecological Concerns. John Wiley and Sons Inc., New Jersey, USA.

Francis, J., Giles-Corti, B., Wood, L. and Knuiman, M. (2012). Creating sense of community: The role of public space. Journal of Environmental Psychology, 32(4), 401-409. https://doi.org/10.1016/j.jenvp.2012.07.002

Gesler, W., Bell, M., Curtis, S., Hubbard, P. and Francis, S. (2004). Therapy by design: evaluating the UK hospital building program. Health \& Place, 10(2), 117-128. https://doi.org/10.1016/S1353-8292(03)00052-2

Grant, E. M. (2011). Report: Christies Beach Aboriginal Children and Family Centre: Indigenous Design Considerations. Department of Transport, Energy and Infrastructure, Adelaide, Australia.

Hahn, T. (2012). [Re]Connection. MSc thesis, University of Tennessee, Knoxville, USA.

Han, K. T. (2003). A reliable and valid self-rating measure of the restorative quality of natural environments. Landscape and Urban Planning, 64, 209-232. https://doi.org/10.1016/S0169-2046(02)00241-4

Hartig, T., Mang, M. and Evans, G. W. (1991). Restorative Effects of Natural Environment Experiences. Environment and Behavior, 23(1), 3-26. https://doi.org/10.1177/0013916591231001

Hartig, T., Böök, A., Garvill, J., Olsson, T., and Gärling, T. (1996). Environmental influences on psychological restoration. Scandinavian Journal of Psychology, 37(4), 378-393. https://doi.org/10.1111/j.1467-9450.1996.tb00670.x 
Heerwagen, J. (2009). Biophilia, health, and well-being. In: Campbell, L., and Wiesen, A.

(Eds.), Restorative commons: creating health and well-being through urban landscapes, 38-57. Department of Agriculture, Washington D.C., USA.

Heerwagen, J. H., and Orians, G. H. (1993). Affect and aesthetics: Humans, habitats, and aesthetics. In Kellert, S. R., and Wilson, E. O. (Eds.) The biophilia hypothesis, 138-172. Island Press, Washington D.C., USA.

Hewstone, M., Fincham, F. D. and Foster, J. (2005). Psychology. Blackwell Publishing, New Jersey, USA.

Joye, Y. (2007). Architectural lessons from environmental psychology: The case of biophilic architecture. Review of General Psychology, 11, 305. https://doi.org/10.1037/10892680.11.4.305

Kandel, E. R. et al. (2013). Principles of neural science. 5th ed. McGraw-Hill, New York, USA. Kaplan, R. and Kaplan, S. (1989). The Experience of Nature: A Psychological Perspective. Cambridge University Press, Cambridge, England.

Karlin, B. E. and Zeiss, R. A. (2006). Best practices: environmental and therapeutic issues in psychiatric hospital design: toward best practices. Psychiatr Serv, 57(10), 1376-8. https://doi.org/10.1176/ps.2006.57.10.1376

Kopacz, J. (2004). Color in three-dimensional design. McGraw Hill Professional, New York, USA.

Kozhevnikov, M. (2007). Cognitive styles in the context of modern psychology: toward an integrated framework of cognitive style. Psychological bulletin, 133(3), 464-81. https://doi.org/10.1037/0033-2909.133.3.464

Liotta, S. J. A., Kuma, K., and Belfiore, M. (2012). Patterns and Layering: Japanese Spatial Culture, Nature and Architecture. Gestalten Verlag, Berlin, Germany.

Lüscher, M. (1990). The Lüscher color test. Simon and Schuster, New York, USA.

McCullough, C. S. (2009). Evidence-Based Design For Healthcare Facilities. Sigma Theta Tau International, Indianapolis, USA.

MIZAN, J. \& BALLARD, K. (2005). A qualitative study exploring the effect of the built environment on the doctor - patient interaction in Primary Care. US patent application. MOORE, R. W. (1982). Open-Mindedness and Proof. School Science and Mathimatics, 82(6), 478-480. 
NEVALA, N. \& Tamminen-Peter, L. (2004). Ergonomics and Usability of an Electrically Adjustable Shower Trolley. International Journal of Industrial Ergonomics, 34(2), 131-138. O'CONNOR, Z. (2011). Colour psychology and colour therapy: caveat emptor. Color Research \& Application, 36, 229-234.

OU, L. C., LUO, M. R., WOODCOCK, A. \& WRIGHT, A. (2004). A study of colour emotion and colour preference. part II: colour emotions for two-colour combinations. Color Research \& Application, 29, 292-298.

PASSER, M. W. \& SMITH, R. E. (2012). Psychology: The Science of Mind and Behaviour Paperback McGraw-Hill Higher Education; 2 edition.

PATI, D., Harvey, T. E., Willis, D. A. \& Pati, S.(2015). Identifying Elements of the Health Care Environment that Contribute to Wayfinding. HERD: Health Environments Research \& Deesign Journal, 8(3), 44-67.

PRICE, A. D. F. \& LU, J. (2012). Impact of hospital space standardization on patient health and safety. Architectural Engineering and Design Management, 9, 49-61.

RATCLIFFE, E., GATERSLEBEN, B. \& SOWDEN, P. T. (2013). Bird sounds and their contributions to perceived attention restoration and stress recovery. Journal of Environmental Psychology, 36, 221-228.

SALINGAROS, N. A. (1995). The laws of architecture from a physicist's perspective. Physics Essays, 8, 638-643.

SALONEN, H., LAHTINEN, M., LAPPALAINEN, S., NEVALA, N., KNIBBS, L. D., MORAWSKA, L. \& REIJULA, K. (2013a). Design approaches for promoting beneficial indoor environments in healthcare facilities: a review. Intelligent Buildings International, 5, 26-50.

SALONEN, H., LAHTINEN, M., LAPPALAINEN, S., NEVALA, N., KNIBBS, L. D., MORAWSKA, L. \& REIJULA, K. (2013b). Physical characteristics of the indoor environment that affect health and wellbeing in healthcare facilities: a review. Intelligent Buildings International, 5, 3-25.

SCANNELL, L. \& GIFFORD, R. (2010). Defining place attachment: A tripartite organizing framework. Journal of Environmental Psychology, 30, 1-10.

SCHREUDER, E., VAN ERP, J., TOET, A. \& KALLEN, V. L. (2016). Emotional Responses to Multisensory Environmental Stimuli. SAGE Open, 6, 2158244016630591.

SHELDON, H., SINAYUK, L. \& DONOVAN, S. (2009a). Designing GP buildings. In: INSTITUTE, P. (ed.) STAFF AND PATIENT PRIORITIES FOR THE DESIGN OF COMMUNITY HEALTHCARE FACILITIES IN LAMBETH. UK: Picker Institute Europe. 
SHELDON, H., SINAYUK, L. \& DONOVAN, S. (2009b). Designing GP buildings: STAFF AND PATIENT PRIORITIES FOR THE DESIGN OF COMMUNITY HEALTHCARE FACILITIES IN LAMBETH. London: PICKER INSTITUTE EUROPE.

SOLLI, M. \& LENZ, R. (2011). Color emotions for multi-colored images. Color Research \& Application, 36, 210-221.

SPRINGER, T. (2007). Ergonomics for the Healthcare Environment. Geneva, IL, HERO, Knoll.

SUNDELL, J., LEVIN, H., NAZAROFF, W. W., CAIN, W. S., FISK, W. J., GRIMSRUD, D. T., GYNTELBERG, F., LI, Y., PERSILY, A. \& PICKERING, A. (2011). Ventilation rates and health: multidisciplinary review of the scientific literature. Indoor Air, 21, 191-204.

TSUNETSUGU, Y., MIYAZAKI, Y. \& SATO, H. (2005). Visual effects of interior design in actualsize living rooms on physiological responses. Building and Environment, 40, 1341-1346.

ULRICH, R.S. (1983). Aesthetic and affective response to natural environment. In I. Altman \& J. Wohlwill (Eds.), Human Behavior and Environment, Vol.6: Behavior and Natural Environment, New York: Plenum, 85-125.

ULRICH, R. S., et al. (1991). Stress recovery during exposure to natural and urban environments. Journal of Environmental Psychology, 11, 201-230.

ULRICH, R. (1993). Biophilia, biophobia, and natural landscapes. Biophilia, Biophobia, and Natural Landscapes. 73-137.

ULRICH, R., et al. (2004). The Role of the Physical Environment in the Hospital of the 21st Century. Report sponsored by The Robert Wood Johnson Foundation and The Center for Health Design.

ULRICH, R. S., et al. (2008). A review of the research literature on evidence-based healthcare design. Health environments research \& design journal, 1, 61-125.

VAN DEN BERG, A. E., HARTIG, T., \& STAATS, H. (2007). Preference for Nature in Urbanized Societies: Stress, Restoration, and the Pursuit of Sustainability. Journal of Social Issues, 63(1), 79-96.

VAN WAGNER, K. (2009). Color psychology: How colors impact moods, feelings and behaviours. Psychology.

WASTIELS, L., SCHIFFERSTEIN, H. N., HEYLIGHEN, A. \& WOUTERS, I. (2012). Relating material experience to technical parameters: A case study on visual and tactile warmth perception of indoor wall materials. Building and Environment, 49, 359-367.

WATTS, A. (2010). Tao: The watercourse way, Souvenir Press. 
WINKEL, G., SAEGERT, S. \& EVANS, G. W. (2009). An ecological perspective on theory, methods, and analysis in environmental psychology: Advances and challenges. Journal of Environmental Psychology, 29, 318-328.

WOHLWILL, J. F. (1983). The concept of nature: A psychologist's view. Human Behavior \& Environment: Advances in Theory \& Research, 6, 5-37. 